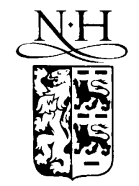

\title{
Nanostructures on the $\mathrm{SrTiO}_{3}(001)$ surface studied by STM
}

\author{
Martin R. Castell \\ Department of Materials, University of Oxford, Parks Road, Oxford OX1 3PH, UK \\ Received 15 March 2002; accepted for publication 21 June 2002
}

\begin{abstract}
Atomic resolution scanning tunnelling microscopy of the $\mathrm{SrTiO}_{3}\left(\begin{array}{ll}0 & 0\end{array}\right)$ surface reveals that certain treatments give rise to two types of self-assembled nanostructures. Surfaces prepared through $\mathrm{Ar}$ ion sputtering and ultrahigh vacuum (UHV) annealing up to $900{ }^{\circ} \mathrm{C}$ form terraces with straight step edges that have a $\mathrm{c}(4 \times 2)$ reconstruction. Following further UHV annealing above $900{ }^{\circ} \mathrm{C}$ nanolines of $1 \mathrm{~nm}$ width, $0.2 \mathrm{~nm}$ height, and variable length are created that run in $\langle 100\rangle$ directions. On closest packing the nanolines are $2.4 \mathrm{~nm}$ apart and form a $(6 \times 2)$ overlayer. On further annealing the nanolines break up into nanodots of $0.2 \mathrm{~nm}$ height that form regular arrays. It is proposed that both structure types are created through non-stoichiometry of the surface region that results in nanocrystalline growth of either $\mathrm{SrO}$ or $\mathrm{TiO}_{x} . \mathrm{SrTiO}_{3}$ surfaces patterned in this way have the potential to serve as a template for the growth of metallic or semiconducting quantum structures.
\end{abstract}

(c) 2002 Elsevier Science B.V. All rights reserved.

Keywords: Scanning tunneling microscopy; Surface relaxation and reconstruction; Surface structure, morphology, roughness, and topography; Low index single crystal surfaces; Surface defects

\section{Introduction}

The technological realization of novel electronic devices such as single electron transistors and quantum dot lasers will ultimately rely on the growth of self-assembled arrays of nanometre sized structures. Research in this field has to date been dominated by semiconducting materials systems, for example the growth of Ge islands on $\mathrm{Si}$ substrates [1,2] or $\mathrm{ErSi}_{2}$ nanowire creation on $\mathrm{Si}[3]$. While there have been many successes, the nanostructures that are grown are generally not well ordered and can have significant size distributions

\footnotetext{
E-mail address: martin.castell@materials.ox.ac.uk (M.R. Castell).
}

which degrade their usefulness. As a possible solution to these difficulties, studies on other materials systems have been initiated. Some insulating oxide crystals are particularly attractive candidates because nanostructures grown on them will be electrically insulated from the substrate. In this paper it is shown how modification of the $\mathrm{SrTiO}_{3}\left(\begin{array}{lll}0 & 0 & 1\end{array}\right)$ surface gives rise to growth of nanoline and nanodot arrays. It is proposed that these structures could be used as arrays of nanowires and quantum dots. The patterned surfaces might also act as a suitable substrate for the growth of new metallic or semiconducting quantum structures.

Interest in $\mathrm{SrTiO}_{3}$ surfaces and interface structures has emerged from its extensive use as a substrate for high $T_{\mathrm{c}}$ superconductor film growth. $\mathrm{SrTiO}_{3}$ is also a candidate for a crystalline gate 
dielectric in silicon based devices [4,5] and is used as an interface layer to allow GaAs to be grown on Si [6]. Despite extensive research into the surface properties of $\mathrm{SrTiO}_{3}(001)$ there remain many open questions regarding surface terminations, ferroelectric properties $[7,8]$, and reconstructions [9-20].

$\mathrm{SrTiO}_{3}$ crystallizes into the cubic perovskite structure with a $0.3905 \mathrm{~nm}$ lattice parameter and formal ionic charges of $\mathrm{Sr}^{2+}, \mathrm{Ti}^{4+}$, and $\mathrm{O}^{2-}$. The crystal viewed in the $\langle 001\rangle$ directions is made up from a stack of alternating $\mathrm{TiO}_{2}$ and $\mathrm{SrO}$ layers, so that two charge neutral $\left(\begin{array}{lll}0 & 0 & 1\end{array}\right)$ bulk terminations of this crystal are possible: the SrO surface, and the $\mathrm{TiO}_{2}$ surface. One would expect a $\left(\begin{array}{lll}0 & 0 & 1\end{array}\right)$ surface of a cut and polished crystal to have both types of termination. However, the $\mathrm{SrO}$ termination of the two termination $(1 \times 1)$ surface can be removed through a chemical etch. Ion scattering spectroscopy showed that with the use of this etch it is possible to create substrates that are predominantly $\mathrm{TiO}_{2}$ terminated [21-24]. In its stoichiometric form $\mathrm{SrTiO}_{3}$ is a good insulator with a 3.2 $\mathrm{eV}$ bandgap, but $\mathrm{n}$-type behaviour can be achieved through substitutional doping with $\mathrm{Nb}^{5+}$ on a $\mathrm{Ti}$ site which makes the crystals sufficiently electrically conducting to allow successful scanning tunnelling microscope/microscopy (STM) imaging.

Previous surface structure studies of $\mathrm{SrTiO}_{3}$ (0 0101$)$ have revealed a large number of reconstructions depending on the surface preparation conditions [9-20]. The interpretation of this data is complicated by a number of factors including nonstoichiometry of the surface layer, the possibility of simultaneously having $\mathrm{TiO}_{2}$ and $\mathrm{SrO}$ crystal terminations present, and the effect of surface segregation of impurities. Generally, most reconstructions have been attributed to ordering of oxygen defects. In this paper the focus is on previously unreported nanostructures that emerge on the $c(4 \times 2)$ reconstructed surface.

\section{Experimental method}

$\mathrm{Nb}$-doped $\mathrm{SrTiO}_{3}$ single crystals with epi-polished $\left(\begin{array}{lll}0 & 0 & 1\end{array}\right)$ surfaces were supplied by PI-KEM,
Surrey, UK. The $0.5 \%$ molar Nb content was determined through proton induced X-ray emission measurements and other impurity levels, notably $\mathrm{Ca}$, were below the detection level of around $0.1 \%$. The high level of $\mathrm{Nb}$ doping resulted in a low room temperature resistivity of $10^{-3} \Omega \mathrm{m}$ which increased with increasing sample temperature. The $\mathrm{SrTiO}_{3}$ crystals were etched for $10 \mathrm{~min}$ in a buffered $\mathrm{NH}_{4} \mathrm{~F}-\mathrm{HF}$ solution (BHF) of $\mathrm{pH} 4.5$ according to the recipe published by Kawasaki et al. [22] in order to remove any $\mathrm{SrO}$ terminations.

Following the BHF etch the samples were introduced into the ultrahigh vacuum (UHV) chamber of a STM (JEOL JSTM4500XT) operating at a pressure of $10^{-8} \mathrm{~Pa}$. Etched $\mathrm{Pt} / \mathrm{Ir}$ tips were used to obtain constant current images at room temperature with a bias voltage applied to the sample. Low energy electron diffraction (LEED) was carried out in a four-mesh VG Microtech rear view LEED system. Sample heating in the UHV chamber was achieved through passing a current through the substrate which allowed anneal temperatures of up to $1400{ }^{\circ} \mathrm{C}$ to be reached. Temperature measurement was performed through a viewport with an optical pyrometer.

\section{Nanostructure evolution}

BHF etched samples were annealed in UHV at temperatures between 600 and $800{ }^{\circ} \mathrm{C}$ typically for 30 min to remove carbon contamination that results from the etching process as shown by previous researchers $[10,24]$. LEED and STM shows that this treatment gives rise to a two domain $(2 \times 1)$ reconstructed surface $[12,14,20]$. The surface is then sputtered with argon ions (typically 10 min, $500 \mathrm{eV}$ energy, $7 \mu \mathrm{A}$ current) and annealed in UHV. Fig. 1 shows the evolution of the morphology of the $\mathrm{SrTiO}_{3}(001)$ surface following sputtering as a function of increasing anneal temperature and/or anneal time.

The STM image in Fig. 1a shows the surface morphology of a sample that was sputtered and then annealed for $15 \mathrm{~min}$ at $750{ }^{\circ} \mathrm{C}$. Terrace formation is already evident in the image, and the step heights between terraces is $0.4 \mathrm{~nm}$ which corresponds to the height of a full unit cell. In 

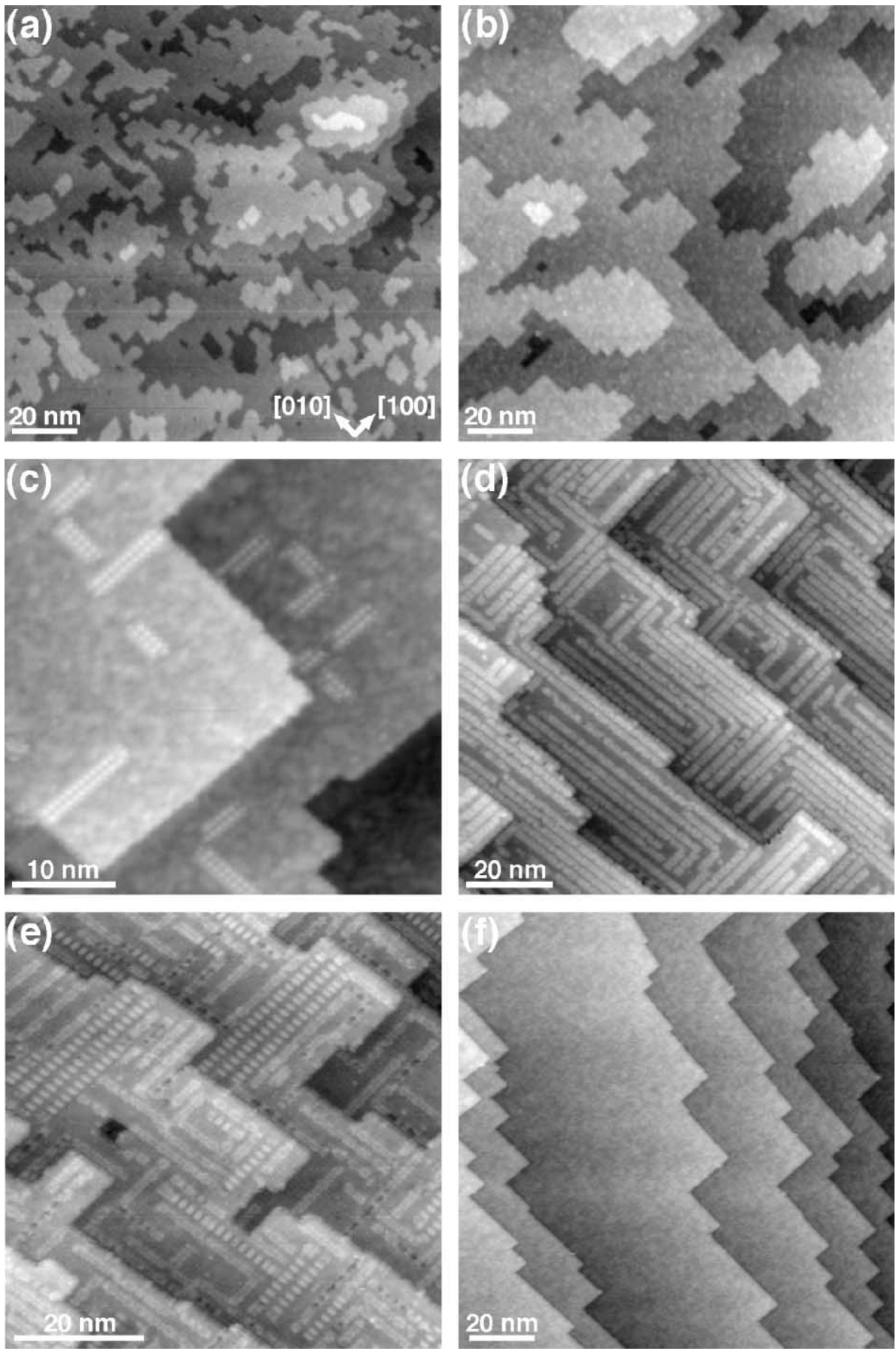

Fig. 1. Sequence of STM images showing the $\mathrm{SrTiO}_{3}\left(\begin{array}{lll}0 & 0 & 1\end{array}\right)$ surface morphology evolution following Ar ion sputtering and annealing in UHV. The images $(\mathrm{a}-\mathrm{f})$ were taken at room temperature following increased anneal temperatures and/or times. The images show: (a) terrace evolution at $750{ }^{\circ} \mathrm{C}$, (b) step edge straightening at $860^{\circ} \mathrm{C}$, (c) nanoline appearance at $950{ }^{\circ} \mathrm{C}$, (d) nanoline self-assembly at 975 ${ }^{\circ} \mathrm{C}$, (e) nanolines breaking up into ordered nanodot arrays at an extended anneal at $900{ }^{\circ} \mathrm{C}$, (f) disappearance of all nanostructures at $1235^{\circ} \mathrm{C}$. The tunnelling currents and sample voltages were: (a) $0.2 \mathrm{nA} / 1.5 \mathrm{~V}$, (b) $0.4 \mathrm{nA} / 1.55 \mathrm{~V}$, (c) $0.3 \mathrm{nA} / 1.5 \mathrm{~V}$, (d) $0.28 \mathrm{nA} / 3.0 \mathrm{~V}$, (e) $0.2 \mathrm{nA} / 2.0 \mathrm{~V}$, (f) $0.2 \mathrm{nA} / 2.0 \mathrm{~V}$. 
Fig. $1 \mathrm{~b}$ the terraces have become larger following an increased anneal temperature of $860{ }^{\circ} \mathrm{C}$ for 5 min and step edge straightening is also evident. The atomic structure that typically covers the terraces of Fig. 1b is shown in the higher resolution image of Fig. 2a which shows the $c(4 \times 2)$ reconstruction with a surface unit cell indicated. As expected, the LEED pattern from this surface corresponds to a two domain $\mathrm{c}(4 \times 2)$ reconstruction shown in Fig. 2c. Additional experimental results and a discussion of the $c(4 \times 2)$ reconstructed surface have been published in a previous paper [20] in which there is also a justification that the $\mathrm{c}(4 \times 2)$ reconstruction is a termination with $\mathrm{TiO}_{2}$ stoichiometry but with only $25 \%$ coverage compared to the $(1 \times 1) \mathrm{TiO}_{2}$ termination.

Fig. 1c is an STM image of the surface when the anneal temperature is raised even further, in this case the sample was annealed for $20 \mathrm{~min}$ at $950{ }^{\circ} \mathrm{C}$. Generally it was found that when anneal temperatures exceeded approximately $870{ }^{\circ} \mathrm{C}$ then nano-
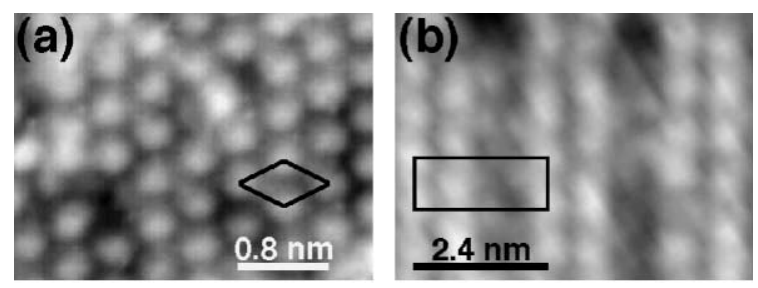

(c)

(d)

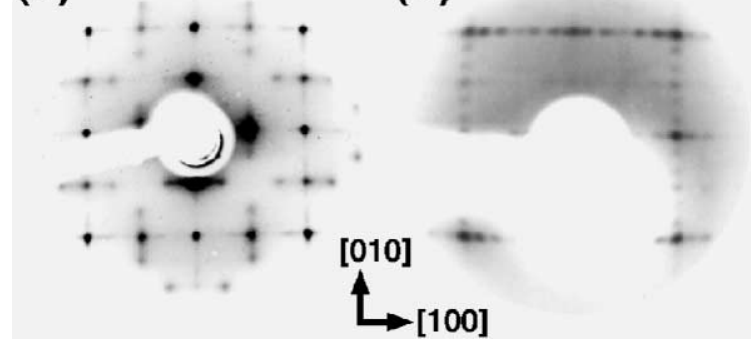

Fig. 2. STM images (a, b) and LEED patterns (c, d) of the $\mathrm{SrTiO}_{3}\left(\begin{array}{lll}0 & 0 & 1\end{array}\right)$ surface reconstructions following Ar ion sputtering and annealing in UHV. In (a) an STM image (0.1 nA tunnelling current, $2.0 \mathrm{~V}$ sample bias) of the $\mathrm{c}(4 \times 2)$ reconstruction is shown and the unit cell indicated. A LEED pattern of the $\mathrm{c}(4 \times 2)$ reconstruction taken at $44 \mathrm{eV}$ is shown in (c). In (b) an STM image $(0.3 \mathrm{nA}$ tunnelling current, $1.0 \mathrm{~V}$ sample bias) of the $(6 \times 2)$ reconstruction is shown with the unit cell indicated. A LEED pattern of the $(6 \times 2)$ reconstruction taken at $72 \mathrm{eV}$ is shown in (d). structures started to appear in the STM images as seen in Fig. 1c. Because these nanostructures are almost invariably atomically straight they will from now on be referred to as nanolines. In the STM images these nanolines appear as double rows of dots and are oriented in the [ 1000$]$ and $\left[\begin{array}{lll}0 & 1 & 0\end{array}\right]$ directions. The structure of the surface around the nanolines is still $\mathrm{c}(4 \times 2)$ reconstructed as determined by atomically resolved STM and LEED.

More prolonged annealing above $900{ }^{\circ} \mathrm{C}$ or hotter annealing causes more nanolines to appear on the surface. Fig. 1d is an STM image of a sample that was annealed at successively higher temperatures up to a final anneal of $975^{\circ} \mathrm{C}$ for 10 min. In this image the nanolines almost entirely cover the surface with only small regions of $c(4 \times 2)$ remaining. When the nanolines are as dense as shown in Fig. 1d they adopt a packing arrangement where the minimum periodicity is approximately $2.4 \mathrm{~nm}$ which is equivalent to a separation of six bulk unit cells. The nanolines themselves have a periodicity of $0.8 \mathrm{~nm}$ along their length equivalent to two bulk unit cells. Therefore, as shown in the STM image in Fig. 2b, when the nanolines dominate the surface coverage a $(6 \times 2)$ reconstruction is formed. This can also be seen in LEED patterns, as shown in Fig. 2d of a two domain $(6 \times 2)$ reconstructed surface. To ensure that the nanolines were not due to surface segregation of impurities X-ray photoelectron spectroscopy (XPS) was carried out on a sample with a similar nanoline coverage to that shown in Fig. 1d. No detectable peaks due to impurities were seen.

When a surface containing many nanolines is annealed for a prolonged period this results in the type of surface that is shown in Fig. 1e. In this STM image a sample was annealed at $900{ }^{\circ} \mathrm{C}$ for $33 \mathrm{~min}$, but a very similar result was also obtained when a sample was annealed at $1000{ }^{\circ} \mathrm{C}$ for 10 min. In Fig. 1e some of the nanolines have been replaced by ordered arrays of dot-like nanostructures, which will be referred to as nanodots. On all samples tested annealing gave rise to nanolines before nanodots, so it is reasonable to assume that the nanodot arrays evolve out of the nanolines. This supposition is further supported by the observation that nanolines can be detected in isola- 
tion (e.g. Fig. 1c and d) but that in all images where nanodots are seen there are also some nanolines present (e.g. Fig. 1e).

When the type of surface shown in Fig. 1e is annealed further, the nanostructures that have formed start to disappear. Fig. If is an STM image of a sample that was annealed at successively higher temperatures up to a final anneal temperature of $1235{ }^{\circ} \mathrm{C}$ for $3 \mathrm{~min}$, and there is no longer evidence of nanostructures. Atomic resolution STM and LEED of this surface show that it has maintained the $\mathrm{c}(4 \times 2)$ reconstruction.

\section{Nanoline and nanodot structure}

As discussed in the previous section and shown in Fig. 1c, annealing conditions can be adjusted to create isolated nanolines on the $\mathrm{SrTiO}_{3}\left(\begin{array}{lll}0 & 0 & 1\end{array}\right)$ surface. An STM image of one of these nanolines is shown in Fig. 3a which was created on a surface that was sputtered and then annealed in UHV at $875^{\circ} \mathrm{C}$ for $22 \mathrm{~min}$. The main feature in the image are the two parallel rows of bright spots that run along the length of the nanoline. The spot separation along the rows and between the rows is 0.8 $\mathrm{nm}$, corresponding to two bulk unit cells. Because the separations are equal, and the spots are opposite each other, this type of nanoline will be referred to as a square nanoline. Towards the righthand side of the nanoline a defect can be seen where one of the spots is missing. The image is of sufficiently high resolution so that further spots can be seen at lower intensity that decorate the outside of the bright spots. The lower intensity spots are located on the sites where there is a gap between the bright spots. The position of a profile across the nanoline is indicated as a black dashed line in Fig. 3a, and the height variation from top to bottom along this profile is shown in Fig. 3b. The graph shows that the nanoline height is around 0.2 $\mathrm{nm}$ above the background level of the surrounding $c(4 \times 2)$ reconstructed surface. Note that the nanoline height corresponds to half a bulk unit cell.

In Fig. 3c an STM image of a long nanoline is shown. The left half of the nanoline is in the square configuration, but towards the centre there is a defect indicated by a white arrow. The right half of the nanoline beyond the defect is in what will be referred to as the zig-zag configuration. The zigzag configuration differs from the square configuration in that the bright spots are no longer opposite each other but one row is shifted along by $0.4 \mathrm{~nm}$ (one bulk unit cell) with respect to the

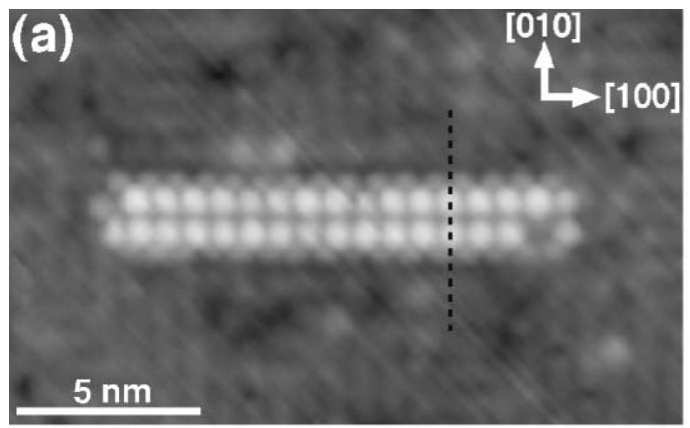

(b)
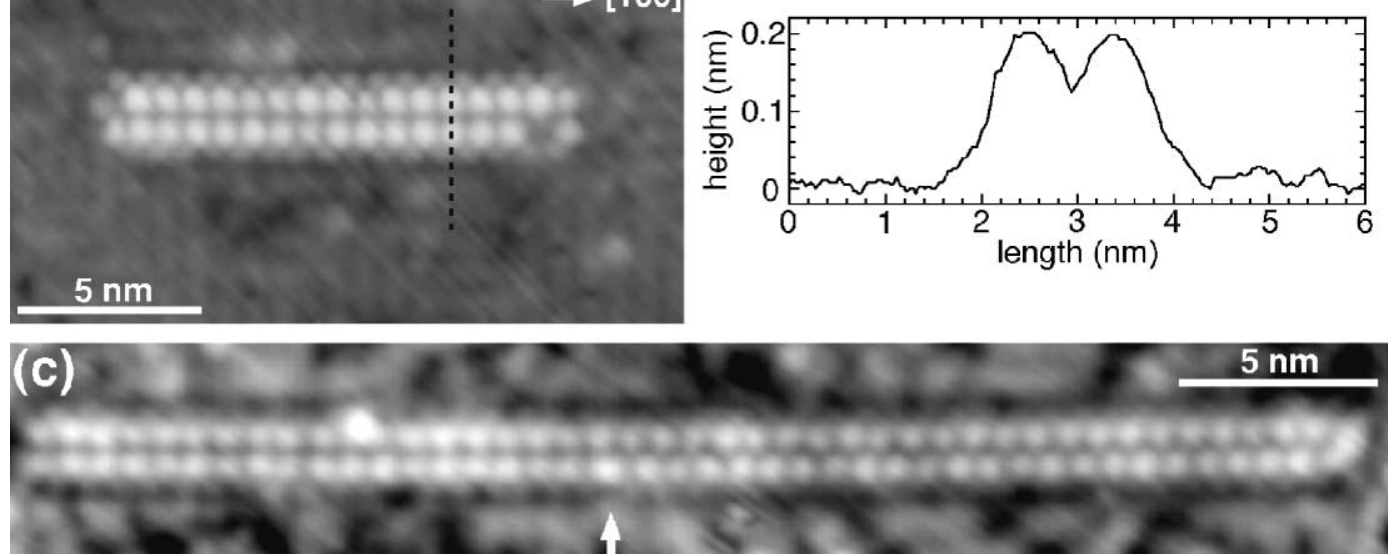

Fig. 3. STM images of nanolines on the $\mathrm{SrTiO}_{3}\left(\begin{array}{ll}0 & 0\end{array}\right)$ surface. In (a) $(0.05 \mathrm{nA}$ tunnelling current, $1.7 \mathrm{~V}$ sample bias $)$ all the main bright features are opposite each other and form a nanoline in a square configuration. The position of a height trace is indicated as a dashed line in (a), and shown in (b). In (c) (0.2 nA tunnelling current, $0.7 \mathrm{~V}$ sample bias) a long nanoline has the square structure on the left side of the image up to a defect indicated with an arrow. Beyond the defect the nanoline adopts the zig-zag structure. 
other. On a nanoline where both square and zigzag configurations are present this means that there must be a point where the spots are separated by an uneven integer multiple of $0.4 \mathrm{~nm}$ rather than the usual $0.8 \mathrm{~nm}$. A defect where the spot separation is $0.4 \mathrm{~nm}$ is indicated with the white arrow in Fig. 3c. Generally speaking, nanolines are either entirely in the square or the zig-zag configuration, with an increasing probability that both configurations are present as nanoline length increases. In the images examined, the square configuration was more prevalent, and approximately two-thirds of the nanolines had square structures and one-third had zig-zag structures.

As stated previously, nanolines are a precursor structure to nanodots, of which a typical array is shown in Fig. 4a. These nanodots were created with the same treatment that was used to create the nanodots in Fig. 1e (i.e. a $900{ }^{\circ} \mathrm{C}$ anneal for 33 min). Further STM images (not reproduced here) as well as some regions in Fig. 1e show that nanolines turn into rows of nanodots, so that the array of nanodots in Fig. 4a would have evolved from a set of horizontal nanolines. A higher magnification STM image of nanodots from another sample is shown in Fig. 4b. Here the nanodots were formed during a $1 \mathrm{~h}$ anneal at $890{ }^{\circ} \mathrm{C}$. The typical vertically elongated cross-shape of the nanodots can be seen, as well as the usual $1.6 \mathrm{~nm}$ horizontal spacing between nanodots along the nanodot rows. In Fig. 4a the vertical spacing between the horizontal nanodot rows is $2.8 \mathrm{~nm}$ (seven bulk unit cells) whereas in Fig. $4 \mathrm{~b}$ the spacing is $3.2 \mathrm{~nm}$ (eight bulk unit cells). The difference in spacing presumably reflects the original spacing of the nanolines from which the nanodots evolved.

The positions of vertical and horizontal profiles across the nanodots are indicated as black dashed lines in the image in Fig. 4b. The vertical height trace running from the top to the bottom of the
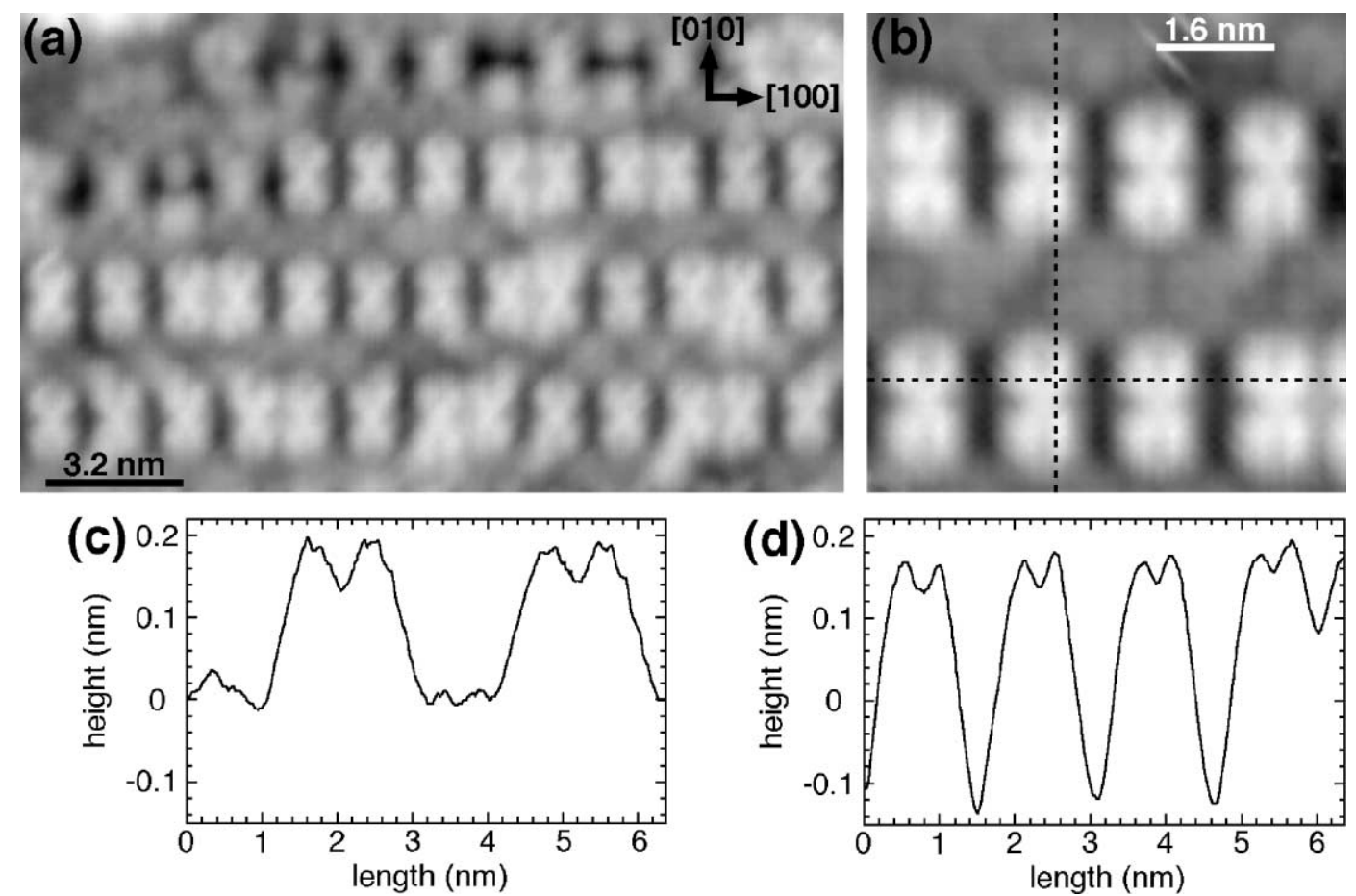

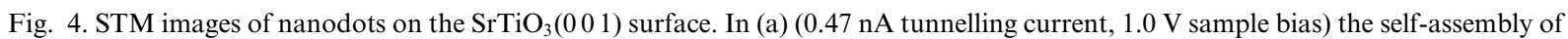
the dots into ordered arrays is seen. In (b) $(0.38 \mathrm{nA}$ tunnelling current, $1.0 \mathrm{~V}$ sample bias) a high resolution image shows that the shape of the dots are elongated crosses. The position of two height traces through (b) are shown in (c) and (d). (c) The vertical trace and (d) is the horizontal trace. 
image is reproduced in Fig. $4 \mathrm{c}$ and shows that the height of the nanodots is $0.2 \mathrm{~nm}$ above the background. The profile also shows that the vertical separation between the maxima within the nanodots is $0.8 \mathrm{~nm}$ which is the same as for the square nanolines.

The horizontal profile running from left to right is shown in Fig. 4d which shows that between the vertical separation of the nanodots the depth drops approximately $0.1 \mathrm{~nm}$ lower that the surrounding background. Presumably the actual depth is $0.2 \mathrm{~nm}$ corresponding to half a unit cell height, but the STM tip is not fine enough to follow the topography contour. The profile also shows that the horizontal separation of the maxima within the nanodots is $0.4 \mathrm{~nm}$, which contrasts with the nanoline features that had a horizontal separation of $0.8 \mathrm{~nm}$.

\section{Discussion}

The immediate issues that arise on studying these STM images of nanolines and nanodots concern their chemical and atomic structure, and the mechanism of their creation. In order to address these questions it is helpful to collate the evidence from the current set of experiments as well as from the related previous study [20]:

1. Nanostructures only form on $\mathrm{SrTiO}_{3}\left(\begin{array}{lll}0 & 0 & 1\end{array}\right)$ surfaces that have the $\mathrm{c}(4 \times 2)$ reconstruction. This reconstruction is created through $\mathrm{Ar}^{+}$ion sputtering and UHV annealing.

2. Nanolines only form at anneal temperatures above around $870{ }^{\circ} \mathrm{C}$. Nanolines can exist in the square or the zig-zag configurations.

3. Nanolines can be transformed to nanodots on further annealing.

4. On annealing to temperatures above approximately $1200{ }^{\circ} \mathrm{C}$ the nanostructures disappear and a $c(4 \times 2)$ reconstructed surface is restored.

Evidence in papers from other researchers includes:

1. Liang and Bonnell $[25,26]$ have published research on $\mathrm{SrTiO}_{3}(001)$ crystals that were an- nealed at $600{ }^{\circ} \mathrm{C}$ for $35 \mathrm{~min}$ in UHV and reported that row-like structures of $0.2 \mathrm{~nm}$ in height were observed in STM images. These structures were attributed to the formation of Ruddlesden-Popper phases [27,28]. The Liang and Bonnell row-like structures are formed at much lower temperatures than the nanolines presented here. Furthermore, the Liang and Bonnell structures have a $0.4 \mathrm{~nm}$ periodicity along the rows, which contrasts with the $0.8 \mathrm{~nm}$ periodicity seen in the nanoline images. For these reasons the nanolines investigated here are thought to be different from the row-like structures observed by Liang and Bonnell $[25,26]$.

2. Liang and Bonnell $[25,29]$ have shown that annealing $\mathrm{SrTiO}_{3}$ in UHV up to approximately $1300{ }^{\circ} \mathrm{C}$ gives rise to $\mathrm{Sr}$ enrichment in the surface region. This is attributed to a higher sublimation rate of $\mathrm{Ti}$ ions versus $\mathrm{Sr}$ ions. Other researchers have observed that a surface with a mixed termination will become preferentially $\mathrm{Ti}$ and $\mathrm{O}$ terminated on annealing in UHV $[30,31]$. On first examination these seem to be contradictory findings, but in fact the surface preparation (including whether the sample was sputtered) and the annealing conditions are crucially important in determining the eventual nature of the surface.

3. Liang and Bonnell $[25,29]$ have shown that annealing $\mathrm{SrTiO}_{3}$ in $\mathrm{UHV}$ at $1300{ }^{\circ} \mathrm{C}$ gives rise to $\mathrm{SrO}$ island formation on the surface. Wei et al. [32] annealed $\mathrm{SrTiO}_{3}$ in an ambient atmosphere at $1300{ }^{\circ} \mathrm{C}$ and showed that this gives rise to $\mathrm{SrO}$ island formation on the surface. Szot and coworkers $[33,34]$ have performed some very elegant atomic force microscopy of the $\mathrm{SrO}$ islands on the $\mathrm{SrTiO}_{3}\left(\begin{array}{ll}0 & 0\end{array}\right)$ surface. The $\mathrm{SrO}$ islands were formed during annealing above $1000{ }^{\circ} \mathrm{C}$ for extended periods (hours) in an oxygen environment.

4. Szot and Speier [33] report that UHV annealing gives rise to $\mathrm{TiO}_{x}$ rich surface phases. Recent work by Maus-Friedrichs [35] has shown that La doped $\mathrm{SrTiO}_{3}\left(\begin{array}{lll}0 & 0 & 1\end{array}\right)$ surfaces develop $\mathrm{TiO}_{x}$ islands on annealing above $1000{ }^{\circ} \mathrm{C}$ in UHV conditions.

5. Transmission electron microscopy (TEM) (e.g. $[36,37])$ has been carried out on perovskite 
crystals that contain non-perovskite phases including Ruddlesden-Popper phases. These studies show very clearly the regions where $\mathrm{TiO}_{2}$ sheets have been removed, resulting in extended layers of $\mathrm{SrO}$ on $\mathrm{SrO}$.

Given the evidence above it is now possible to provide a likely scenario of the changes in surface structure and chemistry following sputtering and annealing as shown in the progression of images in Fig. 1. In Fig. 1a the anneal temperature and/or time is not sufficient to allow extended terrace formation to occur following the $\mathrm{Ar}^{+}$ion sputtering. However, the sputtering process will have caused a degree of non-stoichiometry in the surface region because sputtered and unsputtered surfaces reconstruct differently [20]. The increase in temperature in Fig. 1b allows regular terrace formation to take place, where the surface is covered in a $\mathrm{c}(4 \times 2)$ reconstruction that consists of $\mathrm{Ti}$ and $\mathrm{O}$ ions, see paper [20] for details. In Fig. 1c the increased anneal temperature has caused the local non-stoichiometry in the surface region to express itself through the formation of non-perovskite surfaces phases and these appear as nanolines in the STM image. The further increase in anneal temperature in Fig. 1d and e causes non-perovskite phases to dominate the surface coverage. In Fig. If the high anneal temperature has allowed the nonstoichiometric surface region to diffuse into larger islands of either $\mathrm{SrO}$ or $\mathrm{TiO}_{x}$ composition leaving the surface $\mathrm{c}(4 \times 2)$ reconstructed again.

Given that the nanoline and nanodot composition is likely to be either $\mathrm{SrO}$ rich or $\mathrm{TiO}_{x}$ rich it is possible to speculate on their general structure as shown in Fig. 5. In Fig. 5a a schematic diagram of a $(010)$ cross-section through the $\mathrm{c}(4 \times 2)$ reconstructed surface is shown, see paper [20] for further details. The Ti ions are in light grey, the $\mathrm{Sr}$ ions are in dark grey, and for clarity the oxygen atoms are not shown in the diagram. Fig. $5 b$ and $c$ show cross-sections through $\mathrm{Ti}$ rich nanostructures, where the local stoichiometry of the nanostructures is likely to be $\mathrm{TiO}_{x}$ with $x \leqslant 2$. Proposed $\mathrm{Sr}$ rich nanostructures are shown in Fig. 5d and e. The nanostructure may be composed entirely from $\mathrm{SrO}$ (Fig. 5e), or be $\mathrm{SrO}$ rich but still have a $\mathrm{TiO}_{x}$ surface termination (Fig. 5d). Note that all the
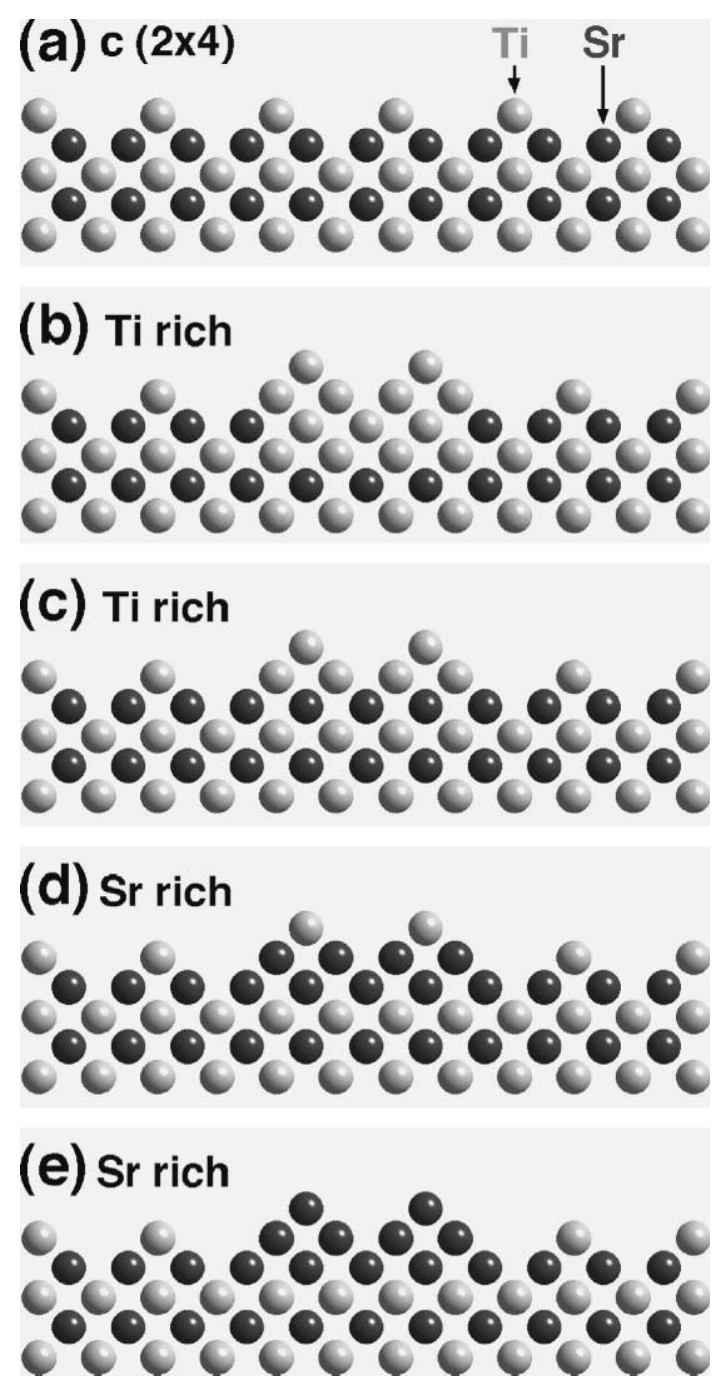

Fig. 5. Cross-sections through the top atomic layers of (a) the $\mathrm{c}(4 \times 2)$ reconstruction, $(\mathrm{b}$ and $\mathrm{c})$ a $\mathrm{TiO}_{x}$ rich surface phase, $(\mathrm{d}$ and e) a $\mathrm{SrO}$ rich surface phase. Ti ions are light, $\mathrm{Sr}$ ions are dark, and $\mathrm{O}$ ions have been omitted.

proposed nanostructures have a half unit cell height above the $c(4 \times 2)$ reconstructed background, as seen in the STM images.

Presumably the non-perovskite phase that appears as a nanoline prefers to grow in 1D rather than $2 \mathrm{D}$ or $3 \mathrm{D}$ due to strain constraints between its crystal structure and the surrounding $\mathrm{SrTiO}_{3}$ lattice. The unit cell dimension in $\mathrm{SrTiO}_{3}$ is 0.3905 $\mathrm{nm}$, whereas the $\mathrm{Sr}-\mathrm{Sr}$ nearest neighbour separation in $\mathrm{SrO}$ with the rocksalt structure is 0.3627 
$\mathrm{nm}$. This represents a tensile strain of $7.1 \%$ for $\mathrm{SrO}$ on $\mathrm{SrTiO}_{3}$ growth which is a viable scenario. Alternatively, the $\mathrm{TiO}$ rocksalt unit cell is $0.424 \mathrm{~nm}$, which would represent $8.4 \%$ compressive strain. The $\mathrm{TiO}_{2}$ anatase structure is also a possibility with a $0.379 \mathrm{~nm}$ unit cell, and hence 3\% tensile strain. However, speculation on possible structures of the nanolines and nanodots would really only be sensible when more is know about their chemical makeup.

If one accepts the scenario of nanostructure creation given above, then it is not possible to relate the structures to the Ruddlesden-Popper phases observed by TEM. Ruddlesden-Popper phases are characterized by a whole missing atomic sheet of $\mathrm{TiO}_{2}$ giving rise to two SrO layers on top of each other. The nanolines shown in this paper are due to $1 \mathrm{D}$ growth along the surface, and are therefore structurally distinct from RuddlesdenPopper phases, although it is possible that they may act as a precursor to them.

\section{Conclusion}

In this paper the creation of nanolines and nanodots is reported. These structures are thought to be due to either $\mathrm{SrO}$ or $\mathrm{TiO}_{x}$ enrichment of the surface region giving rise to nanocrystalline growth of non-perovskite phases on the surface. Strain constraints between the nanostructures and the surrounding $\mathrm{SrTiO}_{3}$ lattice are likely to be responsible for the $1 \mathrm{D}$ growth of the nanolines. If the nanostructures are found to be electrically conducting it would be possible to use them as nanowires and quantum dot arrays. If they are insulating the patterned surfaces could be used as templates for the growth of self-assembled molecular, semiconducting, or metallic structures relevant to quantum devices.

\section{Acknowledgements}

I would like to thank the Royal Society for funding, and Bryan Huey, Thomas Wagner, Peter Hoffmann, Andrew Briggs, Tony Paxton, Karen
Johnston, Mike Finnis and John Pethica for stimulating discussions. I am also grateful to Holger Nörenberg for carrying out the XPS analysis.

\section{References}

[1] G. Medeiros-Ribeiro, A.M. Bratkovski, T.I. Kamins, D.A.A. Ohlberg, R.S. Williams, Shape transition of germanium nanocrystals on a silicon (001) surface from pyramids to domes, Science 279 (1998) 353-355.

[2] F.M. Ross, R.M. Tromp, M.C. Reuter, Transition states between pyramids and domes during $\mathrm{Ge} / \mathrm{Si}$ island growth, Science 286 (1999) 1931-1934.

[3] Y. Chen, D.A.A. Ohlberg, R.S. Williams, Epitaxial growth of erbium silicide nanowires on silicon (001), Mater. Sci. Eng. B-Solid State Mater. Adv. Technol. 87 (2001) 222 226.

[4] R.A. McKee, F.J. Walker, M.F. Chisholm, Crystalline oxides on silicon: the first five monolayers, Phys. Rev. Lett. 81 (1998) 3014-3017.

[5] R.A. McKee, F.J. Walker, M.F. Chisholm, Physical structure and inversion charge at a semiconductor interface with a crystalline oxide, Science 293 (2001) 468-471.

[6] K. Pennicott, GaAs meets its match, Phys. World 14 (2001) 6.

[7] A.A. Sirenko, C. Bernhard, A. Golnik, A.M. Clark, J.H. Hao, W.D. Si, X.X. Xi, Soft-mode hardening in $\mathrm{SrTiO}_{3}$ thin films, Nature 404 (2000) 373-376.

[8] N. Bickel, G. Schmidt, K. Heinz, K. Muller, Ferroelectric relaxation of the $\mathrm{SrTiO}_{3}(100)$ surface, Phys. Rev. Lett. 62 (1989) 2009-2011.

[9] J.E.T. Andersen, P.J. Moller, Impurity induced $900{ }^{\circ} \mathrm{C}$ $(2 \times 2)$ surface reconstruction of $\mathrm{SrTiO}_{3}(100)$, Appl. Phys. Lett. 56 (1990) 1847-1849.

[10] T. Nishimura, A. Ikeda, H. Namba, T. Morishita, Y. Kido, Structure change of $\mathrm{TiO}_{2}$-terminated $\mathrm{SrTiO}_{3}\left(\begin{array}{lll}0 & 0 & 1\end{array}\right)$ surfaces by annealing in $\mathrm{O}_{2}$ atmosphere and ultrahigh vacuum, Surf. Sci. 421 (1999) 273-278.

[11] H. Tanaka, T. Matsumoto, T. Kawai, S. Kawai, Surfacestructure and electronic property of reduced $\mathrm{SrTiO}_{3}\left(\begin{array}{ll}1 & 0\end{array}\right)$ surface observed by scanning tunneling microscopy spectroscopy, Jpn. J. Appl. Phys. Part 1-Regul. Pap. Short Notes Rev. Pap. 32 (1993) 1405-1409.

[12] Q.D. Jiang, J. Zegenhagen, $\mathrm{SrTiO}_{3}(001)$ surfaces and growth of ultra-thin $\mathrm{GdBa}_{2} \mathrm{Cu}_{3} \mathrm{O}_{7-X}$ films studied by LEED/AES and UHV-STM, Surf. Sci. 338 (1995) L882L888.

[13] Q.D. Jiang, J. Zegenhagen, $\mathrm{SrTiO}_{3}(001)$-c $(6 \times 2)$ : a longrange, atomically ordered surface stable in oxygen and ambient air, Surf. Sci. 367 (1996) L42-L46.

[14] Q.D. Jiang, J. Zegenhagen, $\mathrm{c}(6 \times 2)$ and $\mathrm{c}(4 \times 2)$ reconstruction of $\mathrm{SrTiO}_{3}(001)$, Surf. Sci. 425 (1999) 343-354.

[15] P.J. Moller, S.A. Komolov, E.F. Lazneva, Selective growth of a $\mathrm{MgO}(100)-\mathrm{c}(2 \times 2)$ superstructure on a $\mathrm{SrTiO}_{3}(100)$ $(2 \times 2)$ substrate, Surf. Sci. 425 (1999) 15-21. 
[16] M. Naito, H. Sato, Reflection high-energy electron-diffraction study on the $\mathrm{SrTiO}_{3}$ surface-structure, Physica C 229 (1994) 1-11.

[17] T. Matsumoto, H. Tanaka, T. Kawai, S. Kawai, STMimaging of a $\mathrm{SrTiO}_{3}(100)$ surface with atomic-scale resolution, Surf. Sci. 278 (1992) L153-L158.

[18] H. Tanaka, T. Matsumoto, T. Kawai, S. Kawai, Interaction of oxygen vacancies with $\mathrm{O}_{2}$ on a reduced $\mathrm{SrTiO}_{3}$ $(100) \sqrt{5} \times \sqrt{5} R 26.6^{\circ}$ surface observed by STM, Surf. Sci. 318 (1994) 29-38.

[19] T. Kubo, H. Nozoye, Surface structure of $\mathrm{SrTiO}_{3}(100)$ $(\sqrt{5} \times \sqrt{5})-R 26.6^{\circ}$, Phys. Rev. Lett. 86 (2001) 1801-1804.

[20] M.R. Castell, STM of reconstructions on the $\mathrm{SrTiO}_{3}\left(\begin{array}{ll}0 & 01)\end{array}\right.$ surface, Surf. Sci. 505 (2002) 1-13.

[21] A. Ikeda, T. Nishimura, T. Morishita, Y. Kido, Surface relaxation and rumpling of $\mathrm{TiO}_{2}$-terminated $\mathrm{SrTiO}_{3}(001)$ determined by medium energy ion scattering, Surf. Sci. 435 (1999) 520-524.

[22] M. Kawasaki, K. Takahashi, T. Maeda, R. Tsuchiya, M. Shinohara, O. Ishiyama, T. Yonezawa, M. Yoshimoto, H. Koinuma, Atomic control of the $\mathrm{SrTiO}_{3}$ crystal-surface, Science 266 (1994) 1540-1542.

[23] T. Nakamura, H. Inada, M. Iiyama, In situ surface characterization of $\mathrm{SrTiO}_{3}(100)$ substrates and homoepitaxial $\mathrm{SrTiO}_{3}$ thin films grown by molecular beam epitaxy and pulsed laser deposition, Appl. Surf. Sci. 132 (1998) 576-581.

[24] Y. Kido, T. Nishimura, Y. Hoshino, H. Namba, Surface structures of $\mathrm{SrTiO}_{3}(001)$ and $\mathrm{Ni} / \mathrm{SrTiO}_{3}(001)$ studied by medium-energy ion scattering and SR-photoelectron spectroscopy, Nucl. Instrum. Methods Phys. Res. Sect. BBeam Interact. Mater. Atoms 161 (2000) 371-376.

[25] Y. Liang, D. Bonnell, Effect of variations in stoichiometry on the surface-structure of $\mathrm{SrTiO}_{3}(001)$, J. Am. Ceram. Soc. 78 (1995) 2633-2640.
[26] Y. Liang, D.A. Bonnell, Atomic structures of reduced $\mathrm{SrTiO}_{3}(001)$ surfaces, Surf. Sci. 285 (1993) L510-L516.

[27] S.N. Ruddlesden, P. Popper, New compounds of the $\mathrm{K}_{2} \mathrm{NiF}_{4}$ type, Acta Cryst. 10 (1957) 538-539.

[28] S.N. Ruddlesden, P. Popper, The compound $\mathrm{Sr}_{3} \mathrm{Ti}_{2} \mathrm{O}_{7}$ and its structure, Acta Cryst. 11 (1958) 54-55.

[29] Y. Liang, D.A. Bonnell, Structures and chemistry of the annealed $\mathrm{SrTiO}_{3}(001)$ surface, Surf. Sci. 310 (1994) 128134.

[30] A. Hirata, K. Saiki, A. Koma, A. Ando, Electronicstructure of a SrO-terminated $\mathrm{SrTiO}_{3}(100)$ surface, Surf. Sci. 319 (1994) 267-271.

[31] A. Hirata, A. Ando, K. Saiki, A. Koma, Characterization of surface-defects formation in strontium-titanate (100), Surf. Sci. 310 (1994) 89-94.

[32] H. Wei, L. Beuermann, J. Helmbold, G. Borchardt, V. Kempter, G. Lilienkamp, W. Maus-Friedrichs, Study of $\mathrm{SrO}$ segregation on $\mathrm{SrTiO}_{3}(100)$ surfaces, J. Eur. Ceram. Soc. 21 (2001) 1677-1680.

[33] K. Szot, W. Speier, Surfaces of reduced and oxidized $\mathrm{SrTiO}_{3}$ from atomic force microscopy, Phys. Rev. B 60 (1999) 5909-5926.

[34] K. Szot, W. Speier, U. Breuer, R. Meyer, J. Szade, R. Waser, Formation of micro-crystals on the (100) surface of $\mathrm{SrTiO}_{3}$ at elevated temperatures, Surf. Sci. 460 (2000) $112-128$.

[35] W. Maus-Friedrichs, 2002, private communication.

[36] K. Hawkins, T.J. White, Defect structure and chemistry of $($ Caxsr1-X)N +1 tino3n +1 Layer Perovskites, Philos. Trans. R. Soc. Lond. Ser. A-Math. Phys. Eng. Sci. 336 (1991) 541-569.

[37] M.A. McCoy, R.W. Grimes, W.E. Lee, Phase stability and interfacial structures in the $\mathrm{SrO}-\mathrm{SrTiO}_{3}$ system, Philos. Mag. A-Phys. Condens. Matter Struct. Defect Mech. Prop. 75 (1997) 833-846. 